\title{
Determinant Factors of Renal Failure after Coronary Artery Bypass Grafting with On-Pump Technique
}

\author{
Hossein Ahmadi $^{\mathrm{a}} \quad$ Abbasali Karimi $^{\mathrm{a}}$ Saeed Davoodi ${ }^{\mathrm{a}} \quad$ Namvar Movahedi $^{\mathrm{a}}$ \\ Mehrab Marzban ${ }^{a}$ Kyomars Abbasi ${ }^{a} \quad$ Abbas Salehi Omran ${ }^{a}$ Mahmud Shirzad $^{a}$ \\ Seyed Hesameddin Abbasi ${ }^{\mathrm{b}}$ Mokhtar Tazik ${ }^{\mathrm{b}}$
}

Departments of ${ }^{\mathrm{a} C}$ Cardiovascular Surgery and ${ }^{\mathrm{b}}$ Clinical Research, Medical Sciences, Tehran Heart Center,

University of Tehran, Tehran, Iran

\section{Key Words}

Coronary artery bypass grafting $\cdot$ Acute renal failure

\begin{abstract}
Objective: The aim of the present study was to investigate the determinant factors of acute renal failure (ARF) after isolated on-pump coronary artery bypass grafting (CABG). Subjects and Methods: This was a retrospective study of 13,315 adult patients who underwent isolated CABG with cardiopulmonary bypass (CPB) in Tehran Heart Center from May 2002 to May 2007. The exclusion criteria were age $<18$, concomitant cardiac and/or noncardiac surgical operations, history of renal failure before surgery, and chronic renal failure requiring dialysis. Preoperative and operative variables were measured, and a multivariate logistic regression model was constructed to identify the independent risk factors for developing renal failure after on-pump CABG. Results: Of the 13,315 patients, 3,347 (25.4\%) and 90,883 (74.6\%) were females and males, respectively, with a mean age of $58.63 \pm$ 9.48 years. ARF was detected in $85(0.6 \%)$ of the patients with isolated on-pump CABG. The mean age of the patients was $58.63 \pm 9.48$ years, and $25.5 \%$ of them were female. The multivariate logistic regression analysis identified age $(\mathrm{OR}=$ $1.035 ; p=0.002)$, female gender $(O R=1.622 ; p=0.037)$, his-
\end{abstract}

tory of peripheral vascular disease (PVD) $(\mathrm{OR}=2.579 ; \mathrm{p}=$ 0.042), diabetes mellitus $(O R=1.918 ; p<0.001)$, emergent and urgent surgery $(\mathrm{OR}=1.744$ and $\mathrm{OR}=7.901$, respectively; $p=0.003), C P B$ time $>70$ min $(O R=1.944 ; p=0.007)$, and intra-aortic balloon pump (IABP) insertion (OR $=10.181 ; p<$ 0.001 ) as the independent risk factors for ARF. Conclusion: The data showed that age, female gender, positive history of diabetes and PVD, urgent and emergent surgery, CPB time $>70 \mathrm{~min}$, and need for IABP were the independent determinant factors of ARF after on-pump CABG.

Copyright $\odot 2009$ S. Karger AG, Basel

\section{Introduction}

Postoperative acute renal failure (ARF) following cardiopulmonary bypass (CPB) surgery is a serious complication occurring in $2.9-7.7 \%$ of the cases [1] and is associated with a mortality rate varying from 7 to $38 \%$ in patients who require dialysis [2]. The effect of $\mathrm{CPB}$ on renal function is among the causes of renal failure caused by on-pump coronary artery bypass grafting (CABG). Renal dysfunction after $\mathrm{CPB}$ may be related to renal hypoperfusion, nonpulsatile flow, hypothermia, and stimulation of the inflammatory response during the procedure $[3,4]$.

\section{KARGER}

Fax +41613061234

E-Mail karger@karger.ch

www.karger.com
(C) 2009 S. Karger AG, Basel

1011-7571/09/0184-0300\$26.00/0

Accessible online at:

www.karger.com/mpp
Hossein Ahmadi, MD

Associate Professor of Cardiac Surgery

Tehran Heart Center, North Kargar Street

Tehran 1411713138 (Iran)

Tel./Fax +98 218802 9256, E-Mail dr.ahmadi2006@yahoo.com 
Systemic inflammatory response and, consequently, renal injury may result from consecutive events initiated by the contact of plasma proteases and blood cells with the gaseous interface and bioincompatible surfaces of the $\mathrm{CPB}$ machine. The activation of plasma proteases in turn creates proinflammatory mediators, which activate leukocytes, vascular endothelial cells, and platelets which release oxygen-free radicals and lysosomal enzymes, causing a systemic inflammatory reaction and the consequent dysfunction of several organs. This leads to organ failure [5] and preoperative cardiac status instability. It has been reported in a number of publications that several factors can influence renal failure after on-pump CABG, such as emergent surgery, low ejection fraction, and age [6], as well as diabetes mellitus, and male or female gender $[7,8]$. However, there is a dearth of data available on these effective factors among the Iranian population. The objective of this study was to identify the preoperative and operative predictors of renal failure after on-pump isolated CABG.

\section{Subjects and Methods}

This retrospective study, conducted between May 2002 and 2007 , included 13,315 consecutive adult patients who underwent isolated CABG with CPB. All the data were transferred from the computerized surgery data bank of Tehran Heart Center. The exclusion criteria were: age $<18$ years [6], concomitant cardiac and/ or noncardiac operations, history of renal failure (ARF was defined as serum creatinine level $>0.18 \mathrm{mmol} / \mathrm{l}$ [9]) before surgery, and chronic renal failure requiring dialysis to determine other factors that could influence renal dysfunction following surgery. The baseline preoperative variables collected comprised age, gender, body mass index, family history of coronary artery disease, current cigarette smoking, hyperlipidemia, diabetes mellitus, hypertension, ARF, last creatinine level, recent myocardial infarction as defined by the Society of Thoracic Surgeon Adult Cardiac Data definition [10], cerebrovascular disease, peripheral vascular disease (PVD), congestive heart failure, arrhythmia, previous intervention (either surgical or nonsurgical, which may include those done during the current admission), ejection fraction based on angiography and Canadian Cardiovascular Society Angina Score (CCS). The preoperative cardiac status was comprised of the number of coronary arteries involved, left main disease $\geq 50 \%$, and left ventricular ejection fraction [11]. The intraoperative variables measured consisted of emergent surgery, intra-aortic balloon pump (IABP), CPB time, and number of arteries and veins used as grafts. The median of CPB time was $70 \mathrm{~min}$, on the basis of which the patients were divided into two groups of CPB time: $>70$ and $<70 \mathrm{~min}$. Postoperative ARF was defined as serum creatinine level $>0.18 \mathrm{mmol} / \mathrm{l}$ after surgery [12]. The rationale for the selection of the potential risk factors considered in this analysis was based on previous reports [6-8] and our initial validation of the database.

Renal Failure after Coronary Artery Bypass Grafting
Statistical Analysis

The numerical variables were presented as mean \pm standard deviation (SD), while the categorical variables were summarized by absolute frequencies and percentages. The continuous variables were compared using the Student's t test or nonparametric Mann-Whitney $U$ test whenever the data did not appear to have a normal distribution, and the categorical variables were compared using the $\chi^{2}$ test (or Fisher's exact test if required). A multivariate forward stepwise logistic regression model for the risk factors predicting post-CABG renal failure was constructed. The variables were included into the multivariate model if the $p$ value was found to be less than or equal to 0.15 in the univariate analysis. The associations of the independent predictors with postCABG renal failure in the final model were expressed as odds ratio (OR) with $95 \%$ confidence intervals. Model discrimination was measured using the $\mathrm{c}$ statistic, which is equal to the area under the receiver operating characteristic (ROC) curve. Model calibration was estimated using the Hosmer-Lemeshow goodnessof-fit statistic (higher p values imply that the model fits the observed data better). For the statistical analysis, the statistical software SPSS version 13.0 for Windows (SPSS Inc., Chicago, Ill., USA) and the statistical package SAS version 9.1 for Windows (SAS Institute Inc., Cary, N.C., USA) were utilized. All the p values were two-tailed, with statistical significance defined by $\mathrm{p} \leq$ 0.05 .

\section{Results}

Of the 13,315 patients undergoing on-pump CABG, 9,968 (74.5\%) were males and 3,347 (25.4\%) females; average age was $58.63 \pm 9.48$ years. Of the 13,315 patients, ARF occurred in $85(0.6 \%)$. The preoperative variables in the two groups with and without renal failure are given in table 1. Among the preoperative risk factors for CAD, female gender $(p<0.002)$, history of diabetes mellitus $(\mathrm{p}<0.001)$, left main lesion $(\mathrm{p}=0.040)$, PVD $(\mathrm{p}=0.014)$, congestive heart failure $(\mathrm{p}<0.001)$, and CCS score $=$ IV $(\mathrm{p}<0.001)$ were more frequent in the patients with postCABG renal failure. The patients suffering from renal failure were older than the other group $(\mathrm{p}<0.001)$. Urgent and emergent CABG ( $p<0.001)$, IABP insertion $(\mathrm{p}<0.001)$, radial artery used as grafts $(\mathrm{p}=0.016), \mathrm{CPB}$ time $>70$ min $(p<0.001)$, and number of veins used as grafts $(\mathrm{p}=0.002)$ were found more common in the group with ARF than without (table 2). There were no significant differences between the two groups in terms of history of hypertension and arrhythmia, left ventricular ejection fraction, and number of defective coronary vessels. The multivariate logistic regression analysis showed that in the patients with ARF, age, female gender, history of PVD, diabetes mellitus, urgent and emergent CABG, $\mathrm{CPB}$ time $>70 \mathrm{~min}$, and need for IABP insertion were the main predictors of post-CABG renal failure (table 3 ). 
Table 1. Preoperative variables and their association with acute renal failure after $\mathrm{CAB}$

\begin{tabular}{|c|c|c|c|}
\hline Characteristics & $\begin{array}{l}\operatorname{ARF}(+) \\
(n=85)\end{array}$ & $\begin{array}{l}\operatorname{ARF}(-) \\
(\mathrm{n}=13,230)\end{array}$ & $\begin{array}{l}\mathrm{p} \\
\text { value }\end{array}$ \\
\hline Female gender & $34(40.0)$ & $3,347(25.4)$ & 0.002 \\
\hline Male gender & $51(60$ & 6) & 0.102 \\
\hline Body mass index, $\mathrm{kg} / \mathrm{m}^{2}$ & $27.87 \pm 4.11$ & $27.22 \pm 4.04$ & 0.142 \\
\hline Age, years & $62.59 \pm 9.16$ & $58.60 \pm 9.48$ & $<0.001$ \\
\hline Family history of CAD & $33(38.8)$ & $4,813(36.8)$ & 0.701 \\
\hline Hyperlipidemia & $65(76.5)$ & $8,860(67$ & 0.073 \\
\hline Diabetes mellitus & $44(51.8)$ & $4,143(31.04)$ & $<0.001$ \\
\hline Hypertension & $51(60.0)$ & $6,930(52.6)$ & 0.173 \\
\hline Left main lesion & & & 0.040 \\
\hline Cerebrovascular disease & $7(8.2)$ & 962 & 0.740 \\
\hline Peripheral vascular disease & $5(5.9)$ & $218(1.7)$ & 0.014 \\
\hline Congestive heart failure & $21(25.0)$ & $1,503(11.4)$ & $<0.001$ \\
\hline \multicolumn{4}{|l|}{ Recent myocardial } \\
\hline & $40(47.6)$ & $5,135(39.0)$ & 0.105 \\
\hline Previous CABG & & & 0.999 \\
\hline Previous PCI & $1(1.2)$ & $548(4.2)$ & 0.268 \\
\hline Left ventricular EF (\%) & $46.00 \pm 12.57$ & $49.47 \pm 10.26$ & 0.019 \\
\hline Arrhythmia & $5(5.9)$ & $367(2.8)$ & 0.091 \\
\hline CCS score = IV & $18(1.8)$ & $1,001(98.1)$ & $<0.001$ \\
\hline \multicolumn{3}{|c|}{ Number of coronary artery involvement } & 0.137 \\
\hline One vessel & $1(1.2)$ & $569(4.3)$ & \\
\hline Two vessels & $17(20.0)$ & $2,980(22.6)$ & \\
\hline Three vessels & $67(78.8)$ & $9,639(73.1)$ & \\
\hline
\end{tabular}

Data are expressed as absolute frequencies (percentages) or mean $\pm \mathrm{SD}$. CAD = Coronary artery disease $\mathrm{PCI}=$ percutaneous coronary intervention; $\mathrm{EF}=$ ejection fraction.

Table 2. Perioperative risk factors associated with post-CABG renal failure

\begin{tabular}{lccr}
\hline Characteristics & $\begin{array}{l}\text { ARF (+) } \\
(\mathrm{n}=85)\end{array}$ & $\begin{array}{l}\text { ARF }(-) \\
(\mathrm{n}=13,230)\end{array}$ & $\begin{array}{l}\text { p } \\
\text { value }\end{array}$ \\
\hline Status of surgery & & & $<0.001$ \\
$\quad$ Elective & $62(72.9)$ & $11,300(86.0)$ & \\
$\quad$ Urgent & $21(27.7)$ & $1,807(13.8)$ & \\
$\quad$ Emergent & $2(2.4)$ & $26(0.2)$ & \\
IABP insertion & $21(24.7)$ & $287(2.2)$ & $<0.001$ \\
IMA used as graft & $83(97.6)$ & $13,099(99.4)$ & 0.099 \\
Number of IMA for graft & $0.98 \pm 0.22$ & $1.00 \pm 0.15$ & 0.389 \\
Radial artery used as graft & $2(2.4)$ & $1,361(10.3)$ & 0.016 \\
Number of veins for graft & $2.85 \pm 0.92$ & $2.54 \pm 0.90$ & 0.002 \\
CPB time $>70$ min & $59(70.2)$ & $6,421(49.4)$ & $<0.001$ \\
\hline
\end{tabular}

Data are expressed as absolute frequencies (percentages) or mean $\pm \mathrm{SD}$. IMA = Internal mammary artery.

Med Princ Pract 2009;18:300-304
Table 3. Multivariate analysis of perioperative and operative risk factors associated with the development of ARF after CABG

\begin{tabular}{|c|c|c|}
\hline $\begin{array}{l}\text { Component scores } \\
\text { and variables }\end{array}$ & $\begin{array}{l}\text { OR } \\
\text { (95\% confidence interval) }\end{array}$ & $\mathrm{p}$ value \\
\hline \multicolumn{3}{|l|}{ Preoperative items } \\
\hline Age & $1.035(1.010-1.061)$ & 0.002 \\
\hline \multicolumn{3}{|l|}{ Gender } \\
\hline Male & 1.0 (reference) & \\
\hline Female & $1.622(1.028-2.559)$ & 0.037 \\
\hline \multicolumn{3}{|l|}{ PVD } \\
\hline Negative & 1.0 (reference) & \\
\hline Positive & $2.579(1.002-6.639)$ & 0.042 \\
\hline \multicolumn{3}{|l|}{ Diabetes mellitus } \\
\hline Negative & 1.0 (reference) & \\
\hline Positive & $1.918(1.229-2.995)$ & $<0.001$ \\
\hline \multicolumn{3}{|l|}{ Operative items } \\
\hline Type of surgery & & 0.003 \\
\hline Elective & 1.0 (reference) & \\
\hline Emergent & $1.744(1.047-2.907)$ & \\
\hline Urgent & $7.901(1.700-36.728)$ & \\
\hline $\mathrm{CPB}$ time $>70 \mathrm{~min}$ & $1.944(1.200-3.150)$ & 0.007 \\
\hline \multicolumn{3}{|l|}{ IABP insertion } \\
\hline Negative & 1.0 (reference) & \\
\hline Positive & $10.181(5.978-17.341)$ & $<0.001$ \\
\hline
\end{tabular}

Hosmer-Lemeshow goodness-of-fit test; $\mathrm{p}$ value $=0.8166$. Area under the ROC curve (AUC): $c=0.74004$.

\section{Discussion}

Our result confirmed the previous report that acute renal failure after on-pump CABG occurs in $0.7-31 \%$ of cardiac operations [13], and $0.9-4.9 \%$ of the patients tend to require dialytic therapy $[14,15]$. Our data further confirmed that $\mathrm{CPB}$ is a risk factor for developing postoperative renal failure. Hill et al. [16] and Hilberman et al. [30] showed that CPB is characterized by systemic endotoxemia immediately after its onset as well as the systemic release of proinflammatory cytokines, including tumor necrosis factor-alpha and the interleukins 1 and 6, which increased neutrophil-endothelial adherence and subsequent neutrophil organ binding and organ injury during clinical inflammatory conditions. This can be accompanied by an inflammatory response triggered by the contact of blood cells with the bypass machine surface, which causes histamine release, increased vascular permeability, release of oxygen free radicals, and lysosomal enzymes from white blood cells and endothelial 
damage. The consequence of these events is multiorgan insufficiency, known as postperfusion systemic inflammatory response syndrome, which affects target organs such as the kidney. It has been hypothesized that the release of these substances can be the result of the perfusion inadequacy and nonpulsatile blood flow due to the use of standard CPB [17]. CPB also stimulates the production of vasoconstrictors, which diminishes renal blood supply [18]. We also found that CPB time $>70$ min was a predictor of developing post-CABG renal failure. The duration of bypass time has been identified as an important independent risk factor for postoperative renal failure. Whitten et al. [19] reported that CPB duration $<70$ min had fewer effects on postoperative renal failure, whereas Abel et al. [20] and Yallop and Smith [21] could not report the effect of CBP duration on post-CABG renal failure. $\mathrm{CPB}$ is still deemed a major cause of ARF due to medullary ischemia, interstitial edema, tubular obstruction, nephrotoxins, ischemia-reperfusion injury, renal vasoconstriction, renal arterial emboli, and systemic inflammatory response [22]. All these factors become more important if CPB is prolonged. Although we determined that age was associated with high risk of ARF, age is still a controversial risk factor for post-CABG renal failure. A number of studies have reported that renal failure is more likely to occur in older patients, whereas others dispute this view [23-25]. Elderly patients may be susceptible to many forms of ARF because an aging kidney loses function and the ability to withstand acute insults and may have reduced ability to cope with critical circulation [6].

Our finding that female gender was a risk factor for post-CABG renal failure confirmed the findings of Asimakopoulos et al. [8], but not those of Smith et al. [7]. Women have higher post-CABG mortality rates. Some of the suggested contributing factors include increased age, advanced disease co-morbidities, and smaller body surface area [25]. Our multivariate analysis showed that diabetes was a risk factor for post-CABG renal failure, thus confirming the study by McCullough et al. [26] but not that by Chukwuemeka et al. [27]. The effect of diabetes on renal failure after on-pump CABG is controversial; some studies have demonstrated that diabetes increases the risk of post-CABG renal failure [26], while others have reached different results [27]. The effect of diabetes on postoperative renal dysfunction may be related to the result of associated renal parenchymal disease or renal artery stenosis, both of which are more frequent in diabetic subjects [28]. In the present study, our data showed that PVD might be a risk factor for post-CABG renal failure. Stallwood et al. [29] showed the role of PVD on post-
CABG renal failure in a retrospective study. This may be the result of renal parenchymal disease or renal stenosis [28]. Our data showed that IABP insertion was the main predictor of post-CABG renal failure consistent with the study by Zanardo et al. [22]. This device is inserted in order to assist in the maintenance of cardiac output in unstable patients [31]. Postoperative renal function deterioration has been associated with a poor cardiac output state and increased need for IABP support. These postoperative events of preoperative cardiac status instability may further compromise renal perfusion and enhance the effect of renal ischemic events that occur during CPB. The use of IABP may also be associated with the development of ARF if limb ischemia and rhabdomyolysis occur $[32,33]$.

Our data also showed that urgent and emergency surgery could predict post-CABG renal failure because it is a good indicator of a poor preoperative cardiac status situation [24]. In the present study, ARF occurred in 0.6\% of the patients, which is below the range reported in a previous study [13]. In our study, most of the patients had a low mean age and were male (74.5\%). Furthermore, $31.5 \%$ were diabetics and $1.7 \%$ had PVD, which was exceptionally low. Only $30.1 \%$ of our patients had CPB time $>70$ min and only $2.4 \%$ needed emergent surgery. It is worthy of note that only a few studies in the existing literature have used our definition of ARF. Thus, the low prevalence of ARF in our study in comparison with that in previous studies may be due to the above reasons.

There are some limitations to our study: some patients with preoperative renal failure were excluded, as well as those who had concomitant cardiac and/or noncardiac operations. Thus a number of patients who had postoperative renal failure was not included in the study.

\section{Conclusion}

Our data showed that age, female gender, a history of diabetes mellitus and peripheral vascular disease, urgent and emergent surgery, $\mathrm{CPB}$ time $>70 \mathrm{~min}$, and the need for IABP insertion are the determinant factors of renal failure after on-pump isolated CABG. 


\section{References}

1 Loef BG, Epema AH, Smilde TD, Henning RH, Ebels T, Navis G, Stegeman CA: Immediate postoperative renal function deterioration in cardiac surgical patients predicts inhospital mortality and long-term survival. J Am Soc Nephrol 2005;16:195-200.

2 Gamoso MG, Phillips-Bute B, Landolfo KP, Newman MF, Stafford-Smith M: Off-pump versus on-pump coronary artery bypass surgery and postoperative renal dysfunction. Anesth Analg 2000;91:1080-1084.

- 3 Suen WS, Mok CK, Chiu SW, Cheung KL, Lee WT, Cheung D, Das SR, He GW: Risk factors for development of acute renal failure (ARF) requiring dialysis in patients undergoing cardiac surgery. Angiology 1998;49: 789-800.

4 Hall RI, Smith MS, Rocker G: The systemic inflammatory response to cardiopulmonary bypass: pathophysiological, therapeutic, and pharmacological considerations. Anesth Analg 1997;85:766-782.

5 Murphy GJ, Ascione R, Angelini GD: Coronary artery bypass grafting on the beating heart: surgical revascularization for the next decade? Eur Heart J 2004;25:2077-2085.

-6 Landoni G, Bove T, Crivellari M, Poli D, Fochi O, Marchetti C, Romano A, Marino G, Zangrillo A: Acute renal failure after isolated CABG surgery: six years of experience. $\mathrm{Mi}-$ nerva Anestesiol 2007;73:559-565.

7 Smith R, Scarlett M, Soyibo AK, Ramphal P, Irvine R, Barton EN: Acute renal failure post coronary artery bypass grafting at the University Hospital of the West Indies. West Indian Med J 2007;56:300-304.

8 Asimakopoulos G, Karagounis AP, Valencia O, Alexander N, Howlader M, Sarsam MA, Chandrasekaran V: Renal function after cardiac surgery off- versus on-pump coronary artery bypass: analysis using the CockroftGault formula for estimating creatinine clearance. Ann Thorac Surg 2005;79:20242031.

$\checkmark 9$ Brown ML, Holmes DR, Tajik AJ, Sarano ME, Schaff HV: Safety of same-day coronary angiography in patients undergoing elective valvular heart surgery. Mayo Clin Proc 2007; 82:572-574

10 www.sts.org/file/CoreDef241Book.pdf

11 Davoodi S, Karimi A, Ahmadi H, Marzban M, Movahhedi N, Abbasi K, Salehi Omran A, Shirzad M, Sheikhvatan M, Abbasi H: Early outcome of coronary artery bypass grafting in patients with severe left ventricular dysfunction. J Teh Univ Heart Ctr 2007; 3:167-172.
12 Nuutinen L, Hollmén A: The effect of prophylactic use of furosemide on renal function during open heart surgery. Ann Chir Gynaecol 1976;65:258-266.

13 Pontes JC, da Silva GV, Benfatti RA, Machado NP, Pontelli R, Pontes ER: Risk factors for the development of acute renal failure following on-pump coronary artery bypass grafting. Rev Bras Cir Cardiovasc 2007;22: 484-490.

14 Mangano CM, Diamondstone LS, Ramsay JG, Aggarwal A, Herskowitz A, Mangano DT: Renal dysfunction after myocardial revascularization: risk factors, adverse outcomes, and hospital resource utilization. The Multicenter Study of Perioperative Ischemia Research Group. Ann Intern Med 1998; 128:194-203.

15 Santos FO, Silveira MA, Maia RB, Monteiro MD, Martinelli R: Acute renal failure after coronary artery bypass surgery with extracorporeal circulation: incidence, risk factors, and mortality. Arq Bras Cardiol 2004; 83:150-154.

16 Hill GE, Whitten CW, Landers DF: The influence of cardiopulmonary bypass on cytokines and cell-cell communication. J Cardiothorac Vasc Anesth 1997;11:367-375.

17 Onorati F, Presta P, Fuiano G, Mastroroberto P, Comi N, Pezzo F, Tozzo C, Renzulli A: A randomized trial of pulsatile perfusion using an intra-aortic balloon pump versus nonpulsatile perfusion on short-term changes in kidney function during cardiopulmonary bypass during myocardial reperfusion. Am J Kidney Dis 2007;50:229-238.

18 Lema G, Meneses G, Urzua J, Jalil R, Canessa R, Moran S, Irarrazaval MJ, Zalaquett R, Orellana P: Effects of extracorporeal circulation on renal function in coronary surgical patients. Anesth Analg 1995;81:446-451.

19 Whitten CW, Hill GE, Ivy R, Greilich PE, Lipton JM: Does the duration of cardiopulmonary bypass or aortic cross-clamp, in the absence of blood and/or blood product administration, influence the IL- 6 response to cardiac surgery? Anesth Analg 1998;86:2833.

20 Abel RM, Buckley MJ, Austen WG, Barnett GO, Beck CH, Fischer JE: Acute postoperative renal failure in cardiac surgical patients. J Surg Res 1976;20:341-348.

21 Yallop KG, Smith DC: The incidence and pathogenesis of acute renal failure following cardiac surgery, and strategies for its prevention. Ann Card Anaesth 2004;7:17-31.

22 Zanardo G, Michielon P, Paccagnella A, Rosi P, Caló M, Salandin V, Da Ros A, Michieletto F, Simini G: Acute renal failure in the patient undergoing cardiac operation: prevalence, mortality rate, and main risk factors. J Thorac Cardiovasc Surg 1994;107:1489-1495.
23 Ostermann ME, Taube D, Morgan CJ, Evans TW: Acute renal failure following cardiopulmonary bypass: a changing picture. Intensive Care Med 2000;26:565-571.

24 Bove T, Calabrò MG, Landoni G, Aletti G, Marino G, Crescenzi G, Rosica C, Zangrillo A: The incidence and risk of acute renal failure after cardiac surgery. J Cardiothorac Vasc Anesth 2004;18:442-445.

25 Blankstein R, Ward RP, Arnsdorf M, Jones B, Lou YB, Pine M: Female gender is an independent predictor of operative mortality after coronary artery bypass graft surgery: contemporary analysis of 31 Midwestern hospitals. Circulation 2005;112:1323-1327.

26 McCullough PA, Wolyn R, Rocher LL, Levin $\mathrm{RN}$, O'Neill WW: Acute renal failure after coronary intervention: incidence, risk factors, and relationship to mortality. Am J Med 1997;103:368-375.

27 Chukwuemeka A, Weisel A, Maganti M, Nette AF, Wijeysundera DN, Beattie WS, Borger MA: Renal dysfunction in high-risk patients after on-pump and off-pump coronary artery bypass surgery: a propensity score analysis. Ann Thorac Surg 2005;80: 2148-2153.

28 Thakar CV, Liangos O, Yared JP, Nelson D, Piedmonte MR, Hariachar S, Paganini EP: ARF after open-heart surgery: Influence of gender and race. Am J Kidney Dis 2003;41: 742-751.

29 Stallwood MI, Grayson AD, Mills K, Scawn ND: Acute renal failure in coronary artery bypass surgery: independent effect of cardiopulmonary bypass. Ann Thorac Surg 2004;77:968-972.

30 Hilberman M, Myers BD, Carrie BJ, Derby G, Jamison RL, Stinson EB: Acute renal failure following cardiac surgery. J Thorac Cardiovasc Surg 1979;77:880-888

31 Hilberman M, Derby GC, Spencer RJ, Stinson EB: Sequential pathophysiological changes characterizing the progression from renal dysfunction to acute renal failure following cardiac operation. J Thorac Cardiovasc Surg 1980;79:838-844.

32 Maccario M, Fumagalli C, Dottori V, Bruzzone M, Ciani A, Diana A, Giambuzzi M, Parodi E: Rhabdomyolytic acute renal failure in cardiac surgery: a clinical case. Minerva Anestesiol 1995;61:397-400.

33 Maccario M, Fumagalli C, Dottori V, Grasso AM, Agostini M, Parodi E, Pergolo A, Spagnolo S, Passerone G: The association between rhabdomyolysis and acute renal failure in patients undergoing cardiopulmonary bypass. J Cardiovasc Surg (Torino) 1996;37: 153-159. 